\title{
Trait-based approaches for understanding microbial biodiversity and ecosystem functioning
}

\section{Sascha Krause ${ }^{1,2 *}$, Xavier Le Roux ${ }^{3}$, Pascal A. Niklaus ${ }^{4}$, Peter M. Van Bodegom ${ }^{5}$, Jay T. Lennon ${ }^{6}$, Stefan Bertilsson ${ }^{7}$, Hans-Peter Grossart ${ }^{8,9}$, Laurent Philippot ${ }^{10}$ and Paul L. E. Bodelier ${ }^{1}$}

${ }^{1}$ Department of Microbial Ecology, Netherlands Institute of Ecology (NIOO-KNAW), Wageningen, Netherlands

${ }^{2}$ Department of Chemical Engineering, University of Washington, Seattle, WA, USA

${ }^{3}$ Ecologie Microbienne, CNRS, INRA, Université de Lyon, Université Lyon 1, UMR 5557, USC 1193, Villeurbanne, France

${ }^{4}$ Institute of Evolutionary Biology and Environmental Studies, University of Zurich, Zurich, Switzerland

${ }^{5}$ Subdepartment of Systems Ecology, Department of Ecological Sciences, VU University Amsterdam, Amsterdam, Netherlands

${ }^{6}$ Department of Biology, Indiana University, Bloomington, IN, USA

7 Limnology and Science for Life Laboratory, Department of Ecology and Genetics, Uppsala University, Uppsala, Sweden

${ }^{8}$ Leibniz-Institute for Freshwater Ecology and Inland Fisheries, Berlin, Germany

${ }^{9}$ Institute for Biochemistry and Biology, Potsdam University, Potsdam, Germany

10 INRA, UMR 1347 Agroecologie, Dijon, France

\section{Edited by:}

Anne Bernhard, Connecticut

College, USA

Reviewed by:

Susannah Green Tringe, DOE Joint

Genome Institute, USA

Adam Martiny, University of

California, USA

*Correspondence:

Sascha Krause, Department of

Chemical Engineering, University of

Washington, Seattle, Benjamin Hall

IRB, 616NE Northlake Place,

WA 98195, USA

e-mail:smb.krause@gmx.com
In ecology, biodiversity-ecosystem functioning (BEF) research has seen a shift in perspective from taxonomy to function in the last two decades, with successful application of trait-based approaches. This shift offers opportunities for a deeper mechanistic understanding of the role of biodiversity in maintaining multiple ecosystem processes and services. In this paper, we highlight studies that have focused on BEF of microbial communities with an emphasis on integrating trait-based approaches to microbial ecology. In doing so, we explore some of the inherent challenges and opportunities of understanding BEF using microbial systems. For example, microbial biologists characterize communities using gene phylogenies that are often unable to resolve functional traits. Additionally, experimental designs of existing microbial BEF studies are often inadequate to unravel BEF relationships. We argue that combining eco-physiological studies with contemporary molecular tools in a trait-based framework can reinforce our ability to link microbial diversity to ecosystem processes. We conclude that such trait-based approaches are a promising framework to increase the understanding of microbial BEF relationships and thus generating systematic principles in microbial ecology and more generally ecology.

Keywords: functional traits, ecosystem function, ecological theory, study designs, microbial diversity

\section{BEF RESEARCH-A BRIEF OVERVIEW}

The relationship between biodiversity and ecosystem functioning (BEF) (Table 1) is complex and understanding this elusive link is one of the most pressing scientific challenges with major societal implications (Cardinale et al., 2012). However, previous studies established controversial views on BEF relationships, using approaches which experimentally manipulated biodiversity on the one hand and comparative approaches that correlate diversity and ecosystem functioning across treatments or natural gradients on the other hand (Hooper et al., 2005; Balvanera et al., 2006). In essence, comparative studies cannot unequivocally demonstrate causal effects of biodiversity on ecosystem functions, since apparent correlations may arise for many reasons, including the reverse relationship (e.g., ecosystem functions such as productivity altering biodiversity), or unobserved drivers affecting diversity and/or ecosystem functions. In an effort to better understand mechanisms, BEF-research has increasingly moved toward direct manipulation of diversity under otherwise constant environmental conditions, an approach that can attribute observed responses to the direct biodiversity manipulation. It is important to distinguish these two cases. Approaches based on either comparison across environmental gradients/treatments or direct manipulation of biodiversity often led to conflicting results. For example, increasing productivity caused by resource supply often leads to reduced plant diversity, mainly through enhanced competition for light, and hence apparent negative BEF relationships (Abrams, 1995; Hautier et al., 2009), a pattern that has also been reported in microbial systems (Patra et al., 2005). In contrast, diversity manipulations generally reveal positive biodiversity-productivity relationships (Balvanera et al., 2006). These seemingly contradictory results are in fact consistent when accounting for the interplays between site fertility, diversity, and productivity (Schmid, 2002).

Biodiversity effects on ecosystem functioning mainly arise from niche-related mechanisms that shape interactions of the biological units (e.g., OTUs, species, genotypes, ecotypes, functional groups, or phylogenetic groups) that vary genetically and in the expressed functional traits (see Table 1 for definition). These mechanisms are traditionally classified into three broad groups. First, differentiation in resource niches can lead 
to reduced competition, and an increased community niche size (Table 1). As a result, the associated capture of limiting resources is more efficient and community or ecosystem-level performance increases (Loreau, 2000). Such "complementarity effects" emerge from competition for resources (Salles et al., 2009), and from differences in niches related to pathogens and predation. When host-specific organisms are involved, an increase in diversity typically positively affects ecosystem function. For instance Zhu et al. (2000) demonstrated that genetically diversified rice crops had $89 \%$ greater yield, while a major rice disease had $94 \%$ less severe effects on diversified crops compared to rice monoculture controls. A second group of mechanisms is generally summarized under the term "selection effects," represented by the probability that high diversity communities are more likely to contain species with particular traits that translate into above-average performance. Such effects are typically restricted to few species, and occur at the expense of others. Finally, "facilitation effects" occur when certain species modify environmental conditions in a way that is beneficial for other species (Bruno et al., 2003). A typical example is the presence of legumes and their nitrogen-fixing symbionts that lead to a nutrient enrichment of the ecosystem and improved performance of non-fixing plant species and nitrogenrelated microbial processes (Spehn et al., 2005; Le Roux et al., 2013).

BEF relationships ultimately arise from functional differences among the biological units of which communities are comprised. For instance, in plant communities, functional diversity was the driving factor explaining plant productivity (Tilman, 1997). In another study Norberg et al. (2001) introduced a framework that suggests a linear relationship between variances in phenotypes within functional groups and responses to environmental changes. A later example focused on the role of functional diversity to explain BEF relationships and whether or not this is linked to phylogenetic diversity (Flynn et al., 2011). However, functional traits and the resulting ecological niches are the determinants of species interactions and consequently ecosystem functioning. Traits refer to the physiology, morphology, or genomic characteristics that affect the fitness or function of an organism. Traits can be used to infer its performance under different environmental conditions (Violle et al., 2007), they can be measured or scaled-up at the community level, and eventually be related to community and ecosystem functioning (Violle et al., 2007; Wallenstein and Hall, 2012).

Meta-analyses clearly demonstrated that the relationship between biodiversity and ecosystem functioning has primarily been studied for higher organisms (Balvanera et al., 2006; Cardinale et al., 2012). A systematic search of published papers which refer to microbial diversity and ecosystem functioning nevertheless shows that the total number of papers is quite similar for plant- and microbe-related studies identifying the analysis of BEF relationships as a key objective (Figure 1). However, a closer examination reveals that most microbial BEF studies rely on comparative designs where biodiversity is not directly manipulated (Figure 1).

Microbial BEF research is evolving rapidly (Allison and Gessner, 2012; Bouskill et al., 2012) but microbial ecologists often quantify traits at scales ranging from populations (e.g.,

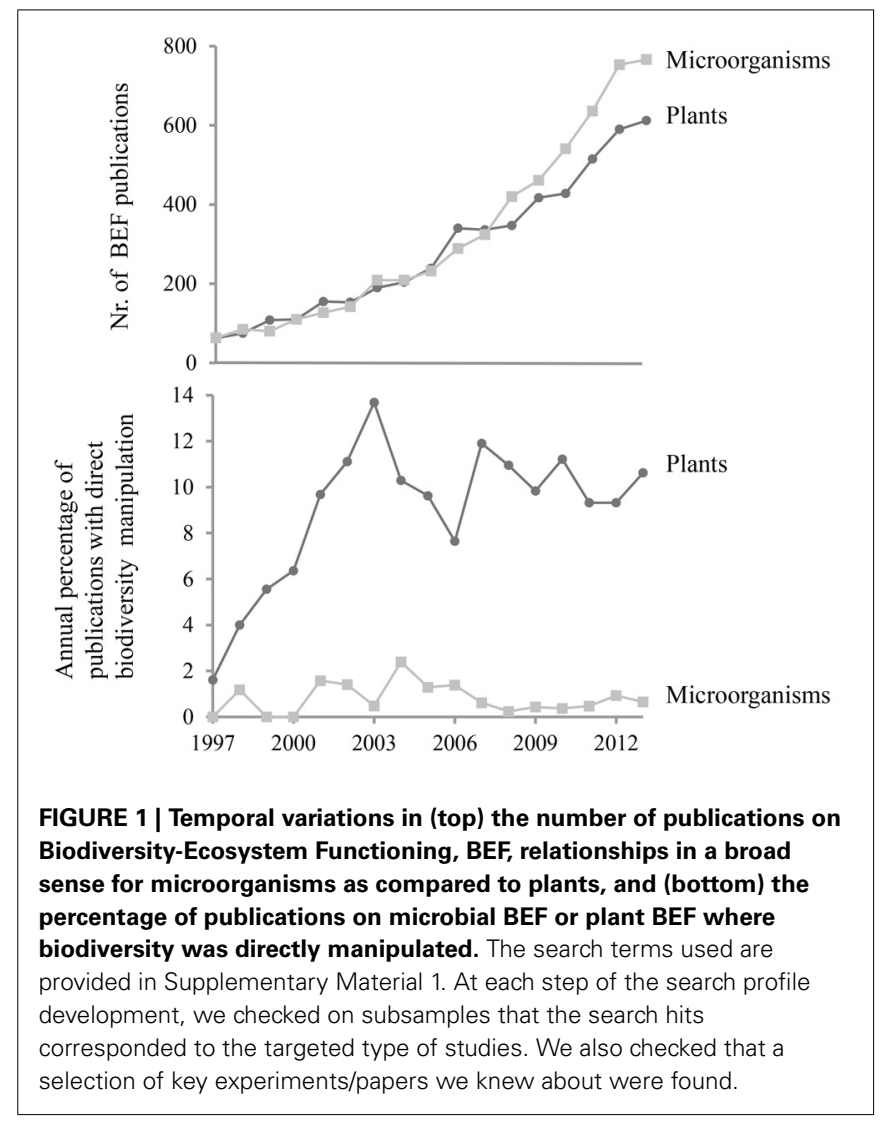

physiological characteristics of strains) to communities (e.g., functional gene pools or substrate utilization patterns from environmental samples) and rarely consider existing trait-related concepts to evaluate BEF relationships as used in ecology. Trait-based approaches could be particularly useful in microbial ecology by complementing microbial approaches based on taxonomy or functional gene/protein sequence diversity and enhancing our ability to link microbial diversity to the functioning of microbial communities and ecosystems.

We review microbial studies relating diversity and process rates, focusing more particularly on the application of traitbased approaches, and identify their current progress and pitfalls. We distinguish the application of trait-based approaches for comparative studies across environmental gradients/treatments (Table 1), and BEF-studies in which biodiversity is manipulated directly (Table 2). We highlight why trait-based approaches could spur significant progress in the understanding of microbial BEF relationships in the future and evaluate how traits can be more directly incorporated into microbial BEF studies. Finally, we discuss the potential and challenges of microbial trait-based approaches to promote the emergence of principles in microbial ecology and BEF relationships in general.

\section{DISTINCTION OF BEF RELATIONSHIPS IN MICROBIAL SYSTEMS \\ COMPARATIVE INVESTIGATION OF MICROBIAL BEF RELATIONSHIPS}

There are many examples where bacterial composition changes along environmental gradients (Hughes Martiny et al., 2006; 
Table 1 | Common terms used in BEF and trait-based BEF approaches.

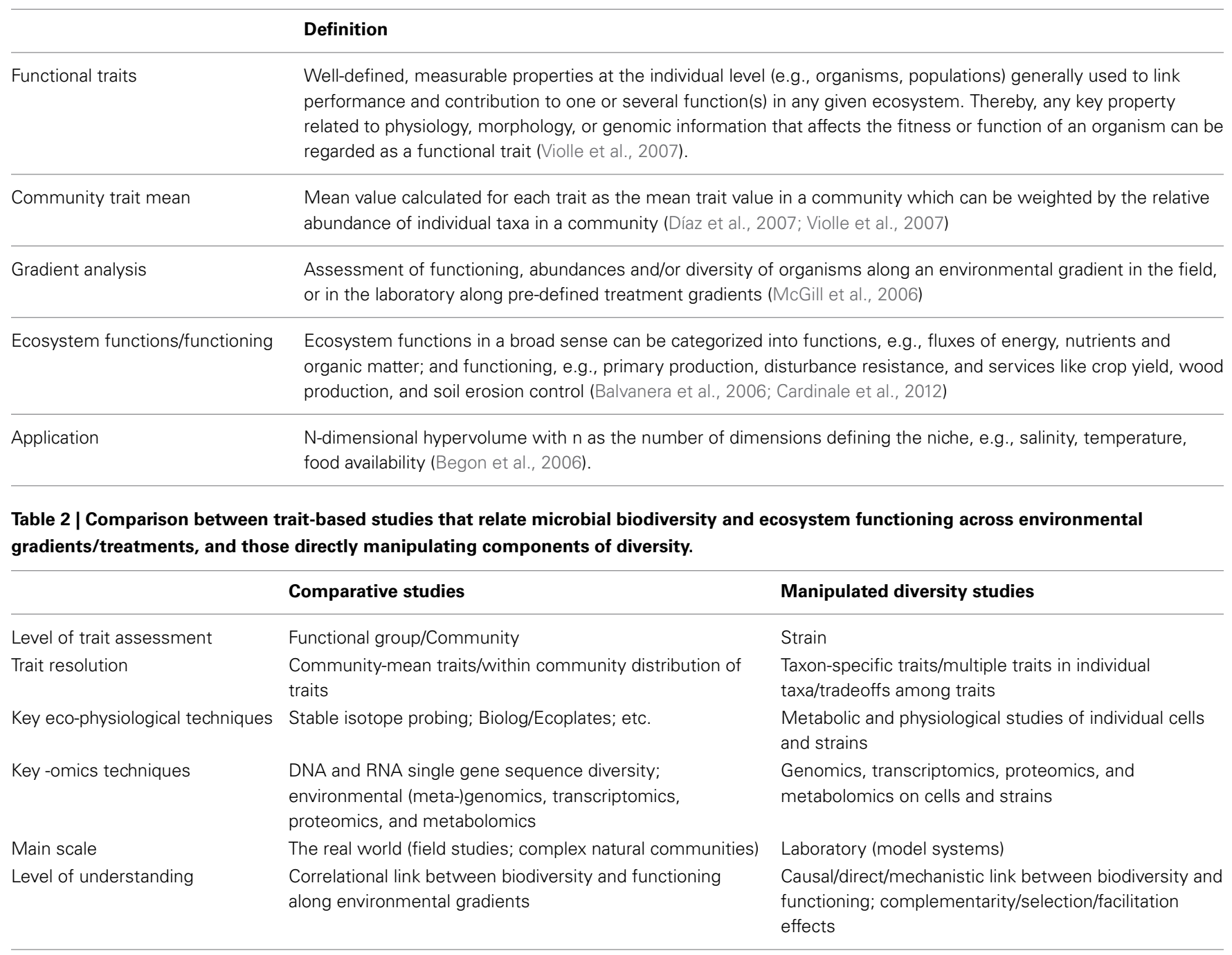

Fierer et al., 2007; Van Der Gucht et al., 2007; Attard et al., 2010; Nemergut et al., 2011; Newton et al., 2011; Ghiglione et al., 2012). However, it is often difficult to mechanistically understand the observed correlation between diversity and function in such comparative approaches, because diversity is an observed, dependent variable rather than an applied treatment. Moreover, many environmental parameters can co-vary with diversity, driving observed relationships.

It is particularly difficult to explain such correlations between microbial diversity and ecosystem function in relation to functional diversity. Many bacterial groups are not available in pure culture, which hinders determination of their physiology and consequently assessment of their functional roles in aquatic and terrestrial environments. Recent evidence suggests that a potentially large portion of the microbial diversity detected in gradient studies are not directly contributing to function, being either dead, in a dormant state or present as extracellular DNA (Lennon and Jones, 2011; Blagodatskaya and Kuzyakov, 2013). Although the "dormant diversity" is part of a microbial seed bank from which different traits can be resuscitated (Lennon and Jones,
2011), it can obscure environmental microbial BEF studies. The use of isotope probing (SIP) represents a way to single out taxa that are actively contributing to function while accounting for non-active, members of a community (Bodelier et al., 2013).

It is crucial to relate a particular process to the diversity of the respective, functionally coherent group; such an analysis has the potential for successfully detecting causal links between microbial diversity and ecosystem function. For instance, some studies reported clear relationships between the diversity of soil ammonia- (Webster et al., 2005) or nitrite-oxidizers and nitrification across management practices in relation to the availability of inorganic nitrogen (Attard et al., 2010). The abundance of soil Nitrobacter, which are nitrite-oxidizing bacteria with high growth rate/specific activity and low $\mathrm{N}$ substrate affinity, increased along a nitrogen gradient (Attard et al., 2010). In contrast, the abundance of Nitrospira, which are nitrite-oxidizing bacteria with low growth rate/specific activity and high $\mathrm{N}$ substrate affinity tended to decrease along this gradient. While in this case both changes in diversity and functioning of nitrite-oxidizers respond to changes along an environmental gradient, diversity changes are important 
in allowing function to increase with increased $\mathrm{N}$ availability. Using a number of traits derived from eco-physiological studies with various guilds of nitrifiers, a trait-based modeling framework successfully predicted a number of functions (i.e. ammonia oxidation, $\mathrm{N}_{2} \mathrm{O}$ emission) in published datasets in various environmental gradients (Bouskill et al., 2012). Of course, this study heavily relies on the coverage of nitrifier diversity by cultured representatives and associated trait information.

A trait-based perspective can facilitate the handling and interpretation of microbial diversity along environmental gradients by measuring functional traits under the specific conditions a given community is exposed to, i.e. as "realized community mean traits." This differs from "a priori" trait values of organisms measured under standardized conditions, and will in part mirror responses to the specific environment and the specific diversity of the community.

\section{DIRECT MANIPULATION OF DIVERSITY TO STUDY MICROBIAL BEF RELATIONSHIPS}

Microbial BEF relationships can also be studied by analyzing the effect of a targeted reduction in microbial biodiversity, e.g., in soil and aquatic microcosms (Le Roux et al., 2011). For instance, reductions in the diversity of pasture soil communities by progressive fumigation or serial dilution had no consistent effect on a range of soil processes (Griffiths et al., 2000, 2004). The removal of diversity for key microbial functional groups such as nitrifiers or denitrifiers provided important information on the extent of functional redundancy within these functional groups (Wertz et al., 2007; Philippot et al., 2013). Reduction of diversity in aquatic microbial communities clearly showed that some metabolic functions (i.e., chitin and cellulose degradation) were controlled by single phylotypes and their traits rather than by richness of the total community (Peter et al., 2011), whereas other functions such as growth were positively correlated to richness. It has to be noted that removal experiments prescribe particular scenarios of diversity loss (e.g., a suspension/dilution approach implies that less abundant species are removed first) which are important for effects on ecosystem functioning (Jones and Lennon, 2010).

An additional step toward understanding the functional role of microbial diversity stems from studies assembling communities through the combination of microbial populations, for example by random selection from a source species pool. This so-called "assemblage approach" has already been used to describe how the diversity of fungal communities influence litter decomposition (Janzen et al., 1995; Cox et al., 2001), the role of mycorrhizal fungal diversity on plant productivity (Van Der Heijden et al., 1998; Jonsson et al., 2001), the role of bacterial diversity on cellulose degradation (Wohl et al., 2004), the role of evenness on the stability of microbial ecosystem functions (Wittebolle et al., 2009), and the role of soil bacterial diversity on mineralization or denitrification (Bell et al., 2005; Salles et al., 2009).

Assemblage experiments offer opportunities to identify mechanisms that may underlie microbial BEF relationships (Le Roux et al., 2011). In particular, functional traits of the assembled strains can be characterized, providing information on whether trait complementarity or selection are major mechanisms for explaining observed BEF relationships (Roscher et al., 2012). For instance, key traits among denitrifying bacteria were linked to the use of different carbon (C) sources that strongly determined the functioning of assembled communities on a mix of C sources (Salles et al., 2009, 2012). The complementarity for traits was a much better predictor of denitrification than taxa richness, the phylogenetic diversity of the communities based on $16 S$ rRNA gene sequences, or even the diversity assessed by functional gene/protein sequences (Salles et al., 2012). In contrast, antagonistic controlling mechanisms were observed for assembled communities of Pseudomonas fluorescens, where inhibition of strains determined the performance of the assembled community (Jousset et al., 2011).

One shortcoming of assemblage experiments is that the assembled, e.g., bacterial communities rarely exceed 100 taxa and hence the diversity is very low compared to the richness observed in most natural communities. Besides, only culturable microorganisms can be used to assemble these communities, even though culture-independent studies suggest the importance of taxa in ecosystem functioning that have not been cultivated (Chen et al., 2008; Mackelprang et al., 2011; Iverson et al., 2012). Nevertheless, studies employing direct manipulation of biodiversity by removal or random assembly of microbial populations remain scarce and represent less than $1 \%$ of published microbial studies focusing on the relationship between diversity and ecosystem functioning (Figure 1). We believe that an increased effort to couple trait-based approaches and assemblage experiments could be a very powerful strategy to specifically identify and decipher the mechanisms underlying microbial BEF relationships.

\section{TRAIT-BASED APPROACHES TO ADVANCE MICROBIAL BEF STUDIES INTEGRATING TRAIT-BASED AND PHYLOGENETIC/TAXONOMIC APPROACHES TO UNDERSTAND MICROBIAL BEF}

Prior to development and adoption of phylogenetic based tools, bacterial taxonomy was based on phenotypes and physiological characteristics that could only be measured in pure cultures (Staley, 2006). Today, the availability of large databases of marker genes (e.g., the Ribosomal Database Project or Greengenes) has enabled the establishment of a detailed classification scheme for microorganisms that also includes those groups that we have not yet been able to cultivate. However, for studying microbial $\mathrm{BEF}$ relationships, a classical taxonomic/phylogenetic approach is hampered by the current species definition (Schleifer, 2009) which can demarcate taxonomic units-which can still be enormously diverse both in functionality and ecology (Staley, 2006; Green et al., 2008). In our opinion, the inherent limitations with regards to the concept of microbial species are not the major issues here, and two other factors are of much more central importance.

To understand BEF relationships it is necessary to study traits at the level of individual cells or organisms (Lavorel et al., 2013). The niches that correspond to traits are hyper-dimensional, and BEF studies call for determining whether niches of functional units overlap. To fully appreciate functional diversity, whether assessed as richness, divergence or dispersion of traits (Hedberg et al., 2013), one has to characterize and account for trade-offs 
among the different traits. For example, plant leaf trait tradeoffs have been shown to affect litter decomposition and therewith the incidence of wild fires (Brovkin et al., 2012), whereas tradeoffs for key traits among bacterial decomposers can restrict the bacterial degradation of recalcitrant carbon to sites with high nitrogen availability (Treseder et al., 2011) and influence how bacteria contend with other abiotic factors such as moisture variability (Lennon et al., 2012). However, characterizing functional trait values and quantifying trade-offs only may lead to spurious correlations and there are only a few examples that demonstrate actual trade-offs supported by plausible physical or chemical mechanisms (e.g., Edwards et al., 2011). Hence, knowledge about trade-offs is indispensable for accurate descriptions of functional BEF relationships and necessitates identification of relevant functional units such as species, ecotypes, or genotypes.

The relevance of trade-offs among microbial traits is recognized (Litchman et al., 2007), but better characterizing trade-offs among microbial traits are likely to be of increasing importance for microbial BEF studies for several reasons. First, they aid in reducing the number of functional dimensions that need to be considered. Second, the co-occurrence of traits and tradeoffs help to define microbial strategies beyond the familiar $r$ vs. $K$ strategies. For example, the life-history scheme designed for plants (Grime, 1977) was used to classify methane-oxidizing bacteria according their competitive ability, ruderal and stress tolerating properties based on culture and environmental traits ( $\mathrm{Ho}$ et al., 2013). This conceptual approach combines information about phylogeny and function and aggregates traits into community responses, allowing for mixed life strategies and offering more flexibility to accommodate the vast metabolic flexibility of bacteria (Figure 2). Though, extrapolation of this conceptual framework to microbial communities deserves experimental validation. There is considerable debate regarding the coherence between phylogeny and the distribution of functional traits (Losos, 2008). If traits are conserved to some degree throughout evolution (trait conservatism), phylogenetic diversity could be a promising proxy for assessing trait diversity. For instance, Cadotte et al. (2008) analyzed 29 studies in which angiosperm biodiversity was manipulated in a systematic way and found that phylogenetic diversity indices explained significantly more variation in

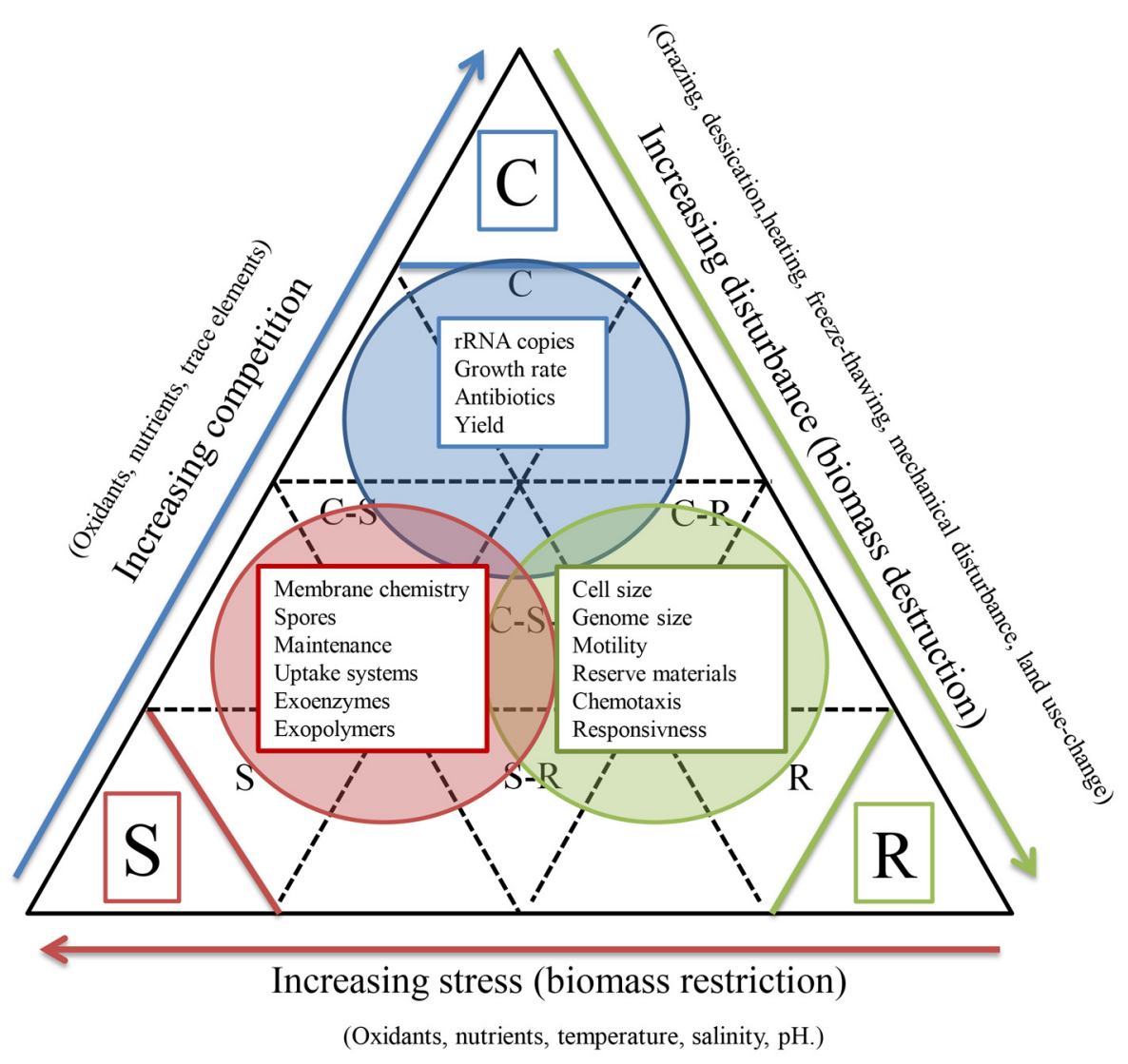

FIGURE 2 | Reflection of microbial traits on the Competitor-Ruderal-Stress tolerator life strategy framework as was proposed for plants (Grime, 1977). The scheme has been adapted for Ho et al. (2013) who used this framework for assigning life-strategies to methane-oxidizing bacteria. The scheme groups subsets of microbial traits which collectively would be of most importance for the respective strategy. The traits collectively accommodate exploring and exploiting habitats, competing with other organisms, tolerating or avoiding surviving stress, and deprivation. This classification is purely qualitative but, for some traits, life-history strategies have been proposed in earlier studies (Fierer et al., 2007; Portillo et al., 2013). 
productivity than plant species richness or other diversity measures that were available. Flynn et al. (2011) analyzed data from 29 experiments involving 174 plant species that were present in 1721 combinations and found that functional trait diversity and phylogenetic diversity explained similar amounts of variation in the observed responses. Interestingly, phylogenetic diversity explained variation in data that was not explained by traits, suggesting that it is a surrogate to quantify trait differences along niche axis that are difficult to assess directly (such as pathogenrelated niches, or complex hyper-dimensional combinations of single traits assessed).

In microbial ecology, the extent to which functional traits are phylogenetically conserved remains unclear. Considering the rather extensive horizontal gene transfer (Polz et al., 2013) likely compromising a unifying phylogenetic framework, functional diversity measures do not necessarily follow either taxonomy, phylogenetic or apparent evolutionary relationships. For instance, variations in key functional traits of denitrifying bacteria were not well correlated to their (16S rRNA-based) phylogenetic relatedness or functional gene/protein sequence relatedness (Jones et al., 2011; Salles et al., 2012). From another perspective, several studies reported broad ecological coherence of high bacterial taxonomic ranks building on $16 S$ rRNA phylogeny (Fierer et al., 2007; Von Mering et al., 2007; Philippot et al., 2009; Lennon et al., 2012). The question thus remains whether or not one should abandon taxonomy- and phylogeny-based approaches altogether for studies of BEF relationships. If traits are phylogenetically conserved at least for some microbial groups, phylogenetic diversity could serve as proxy for functional diversity. Calculating functional diversity indices generally requires the assessment of traits at the individual or some aggregated taxonomic level, which generally is impossible in microbial studies that do not build assemblagebased designs. Martiny et al. (2012) recently developed a new phylogenetic metric which estimates the clade depth of shared traits between organisms. This approach could be used to translate differences in community composition into consequences for microbial-mediated processes. Another approach models evolutionary dynamics of bacteria to ecologically distinct lineages, so called ecotypes, within natural communities, allowing for a highly resolved ecological classification (Koeppel et al., 2008). Such distinction of microbial taxa based on ecological features would bridge the gap between taxonomy- and trait-based approaches in microbial ecology. We argue that trait-based approaches should build on-not replace-taxonomy-based approaches. The information needed to properly characterize the co-occurrence of traits and trait trade-offs among microorganisms builds on taxonomic ranks, and there is certainly an incentive for more highthroughput surveys of phenotypic characteristics of microbial taxa (Bayjanov et al., 2012). Such approaches could mark the beginning of a deviation from classical phylum-based approaches in microbial BEF studies toward a classification based on functional performance and role in the environment.

\section{TOOLS AVAILABLE TO INTEGRATE TRAITS INTO MICROBIAL BEF STUDIES}

Measurements of taxonomic microbial diversity are very challenging since diversity levels are extremely high for most natural microbial systems (Torsvik et al., 2002; Caporaso et al., 2011). To obtain functional diversity measures in microbial BEF studies, the biggest challenges are (i) defining which microbial traits are important with respect to ecosystem functioning or particular ecosystem functions, and (ii) measuring these relevant traits.

For the assemblage studies, microbial ecologists can measure multiple traits for individual microorganisms or populations and quantify tradeoffs between traits. However, defining the types of relevant traits to measure is a challenge, depending on the community functioning under study. On the other hand, traits can be related to shifts in function across environmental gradients or treatments, at the genetic or functional level, or directly at the community scale. However, this is different from analyzing BEFrelationships in the general ecological context, which requires methods capable of quantifying the local functional diversity (i.e., the variation of trait combinations present at the individual level). Community mean traits are not useful for this purpose, since the information about effects of the local trait diversity (i.e., the putative local driver of a BEF-relationship) will be lost by averaging.

The analysis of metabolic processes offers great potential to evaluate aggregated trait values at the community scale. Functional traits can be assessed by high-throughput assays, such as Biolog or Ecoplates. These cultivation-based metabolic assays can be used to characterize the community capacity to oxidize a range of C sources (Garland, 1996) or to measure a functional operating range of soil or aquatic microbial communities (Hallin et al., 2012).

We see some advantage for microbial studies correlating community-mean traits to functional capabilities of the community as a whole, since these are more easily measurable than for higher organisms. Indeed, aggregated trait values would boil down to a metric sizing of "meta-species," which can illuminate responses along environmental gradients and possible effects on ecosystem functioning. A drawback is that the combination of traits of all microbial individuals that compose the community can hardly be characterized.

We can expect that our ability to identify and quantify functional traits of microbial individuals and populations in natural, complex communities will increase in the coming years. Despite the dogma that we cannot study the physiology of ecologically "relevant" microbes from environmental samples owing to the challenges associated with the enrichment and isolation of most taxa, we must recognize that there have already been major advances in cultivation efforts over the past 20 years. In situ enrichments (e.g., diffusion chambers and baited beads) and other incubation methods can be used to determine cellspecific metabolic rates, even at extremely low rates (Hoehler and Jorgensen, 2013). Additional physiological features that are tractable today (without isolation) include cell-size related nutrient affinity and nutrient use efficiency (Edwards et al., 2012), and specific substrate use with isotope tracking methods targeting single cells of different size and shape (flow cytometry and stable isotope tracers, microautoradiography, nano-SIMS) (Nielsen et al., 2003; Casey et al., 2007; Behrens et al., 2012; Garcia et al., 2013). In addition, just like in the omics realm, there have been major advances in microscopy and bio-molecular imaging over 
the last 20 years (Haagensen et al., 2011), with novel and refined techniques that offer huge opportunities to access key aspects of functional diversity, even within complex microbial communities. For instance, we can now have access to the bulk biochemical composition of cells by RAMAN spectroscopy (Huang et al., 2007), and to their spatial organization (Stiehl-Braun et al., 2011). Sensitive fluorescence-based techniques enable visualization of novel morphological and physiological features (porins, flagella, proteins, and protein-coding genes etc.) and of associations based on syntrophic interactions (Watrous et al., 2013). Hence, even if a proper quantification of the functional diversity of natural, complex communities from multiple trait values of individuals composing these communities remains challenging, a toolkit already exists to help microbial ecologists working in this domain. Finally, the dramatically improved opportunities to reconstruct genomes of so far uncultivated microbial populations and cells by binning of complex metagenomes (Rusch et al., 2010; Iverson et al., 2012) has demonstrated great potential for resolving metabolic and functional traits of uncultured and poorly known representatives in the microbial world (Wrighton et al., 2012). This can even be combined with in situ substrate usage of uncultivated microbes (Mayali et al., 2012). Single cell genome sequencing (Stepanauskas, 2012) is another feasible way to elucidate and infer genome encoded traits in uncultured microbial populations that often make up the bulk portion of natural communities and are likely to have a large impact on ecosystem functions.

We believe that microbial ecologist have the ability to provide new insights to trait-based ecology as opposed to just borrowing ideas and approaches from other non-microbial ecologists, fully making use of the particularities of microbial systems and tools. In particular, microbial ecology should play a key role in deciphering the effects of functional diversity and spatial distribution in BEF studies, offering very relevant and manageable models to address this key issue.

\section{CONCLUSION AND PERSPECTIVES}

Microbial communities are a key variable in how natural and anthropogenic disturbances, including climate change, will affect ecosystem functioning and hence delivery of services to human societies. The trait-based approach is not the Holy Grail (Lavorel and Garnier, 2002) but a promising framework and discourse for future microbial research. In particular, promising experimental approaches that incorporate functional traits can pave the road to increase the understanding of microbial BEF relationships, and $\mathrm{BEF}$ relationships in general.

Microbial ecologists face challenges but also great opportunities in this context. Instead of simply suggesting the need to renew approaches in BEF research using traits, we argue that two main priorities for microbial BEF studies are (i) to reinforce experimentally-sound studies of the role of microbial (traitbased) diversity on ecosystem functioning, and (ii) to promote efforts for measuring and archiving microbial traits in a way suitable for the highly diverse and dynamic microbial communities that make up the biosphere.

The first priority arises from the current paucity of microbial ecology in terms of BEF studies that directly manipulate diversity using a trait-based approach. While assembled communities clearly differ from complex communities from natural environments, this does not diminish the value and potential of such studies to disentangle the possible key mechanisms underlying BEF relationships.

Concerning the second priority, we call for more innovative physiological studies in order to measure traits and their relevant unit (e.g., single strains, population, or community-level). More specifically, by measuring traits in a standardized manner, e.g., incubation condition and media, and by applying analogous tests also to organisms we cannot get in pure culture, we may be able to reveal important trait distributions and generate a microbial trait database similar to, e.g., the TRY global traits initiative for plants (Kattge et al., 2011). Microbial ecologists can also capitalize on novel powerful genome sequencing tools being applied to communities or single uncultured cells, which may serve as a tool for predicting ecosystem function from detected (genomic) traits (Raes et al., 2011; Barberan et al., 2012).

Microbial ecologists can provide new insights and concepts to trait-based BEF studies, according to the particularities of microbial systems and the tools available in microbial ecology. For instance, BEF studies over many microbial generations allow researchers to reveal the effect of eco-evolutionary feedbacks on BEF relationships over reasonable time scales. Also, accounting for spatial and temporal niche variability as well as assessing the role of diversity in multiple related ecosystem functions, microbial trait-based approaches may deliver mechanistic insights in areas practically not feasible in higher organisms, thus providing benefits to ecology as a whole, which is still a major challenge for microbial ecologists (Prosser et al., 2007).

\section{ACKNOWLEDGMENTS}

This study was part of the European Science Foundation EUROCORES Programme EuroEEFG and was financially supported by grants from the Netherlands Organization for Scientific Research (NWO) (Grant number 855.01.150) and the German Science Foundation (GR 1540/17-1). Additional financial support was given to Jay $\mathrm{T}$. Lennon by grants from National Science Foundation (DEB 1146149) and the US Department of Agriculture (2013-02775), and to Stefan Bertilsson from the Swedish Research Council. Many thanks to all participants of the ESF EuroEEFG workshop Understanding, managing and protecting microbial communities in aquatic and terrestrial ecosystems: "Exploring the trait-based functional biodiversity approach," held in Wageningen, the Netherlands, 10-13th February, 2013. This publication is publication nr. 5610 of the Netherlands Institute of Ecology.

\section{SUPPLEMENTARY MATERIAL}

The Supplementary Material for this article can be found online at: http://www.frontiersin.org/journal/10.3389/fmicb.2014. 00251/abstract

\section{REFERENCES}

Abrams, P. A. (1995). Monotonic or unimodal diversity-productivity gradients: what does competition theory predict? Ecology 76, 2019-2027. doi: $10.2307 / 1941677$ 
Allison, S. D., and Gessner, M. (2012). A trait-based approach for modelling microbial litter decomposition. Ecol. Lett. 15, 1058-1070. doi: 10.1111/j.14610248.2012.01807.x

Attard, E., Poly, F., Commeaux, C., Laurent, F., Terada, A., Smets, B. F., et al. (2010). Shifts between Nitrospira- and Nitrobacter-like nitrite oxidizers underlie the response of soil potential nitrite oxidation to changes in tillage practices. Environ. Microbiol. 12, 315-326. doi: 10.1111/j.1462-2920.2009.02070.x

Balvanera, P., Pfisterer, A. B., Buchmann, N., He, J. S., Nakashizuka, T., Raffaelli, D., et al. (2006). Quantifying the evidence for biodiversity effects on ecosystem functioning and services. Ecol. Lett. 9, 1146-1156. doi: 10.1111/j.14610248.2006.00963.x

Barberan, A., Fernandez-Guerra, A., Bohannan, B. J. M., and Casamayor, E. O. (2012). Exploration of community traits as ecological markers in microbial metagenomes. Mol. Ecol. 21, 1909-1917. doi: 10.1111/j.1365294X.2011.05383.x

Bayjanov, J. R., Molenaar, D., Tzeneva, V., Siezen, R. J., and Van Hijum, S. A. (2012). PhenoLink-a web-tool for linking phenotype to $\sim$ omics data for bacteria: application to gene-trait matching for Lactobacillus plantarum strains. BMC Genomics 13:170. doi: 10.1186/1471-2164-13-170

Begon, M., Townsend, C. R., and Harper, J. L. (2006). ECOLOGY: From Individuals to Ecosystems. Malden: Blackwell Publishing.

Behrens, S., Kappler, A., and Obst, M. (2012). Linking environmental processes to the in situ functioning of microorganisms by high-resolution secondary ion mass spectrometry (NanoSIMS) and scanning transmission X-ray microscopy (STXM). Environ. Microbiol. 14, 2851-2869. doi: 10.1111/j.14622920.2012.02724.x

Bell, T., Newman, J. A., Silverman, B. W., Turner, S. L., and Lilley, A. K. (2005). The contribution of species richness and composition to bacterial services. Nature 436, 1157-1160. doi: 10.1038/nature03891

Blagodatskaya, E., and Kuzyakov, Y. (2013). Active microorganisms in soil: critical review of estimation criteria and approaches. Soil Biol. Biochem. 67, 192-211. doi: 10.1016/j.soilbio.2013.08.024

Bodelier, P. L. E., Meima-Franke, M., Hordijk, C. A., Steenbergh, A. K., Hefting, M. M., Bodrossy, L., et al. (2013). Microbial minorities modulate methane consumption through niche partitioning. ISME J. 7, 2214-2228. doi: 10.1038/ismej.2013.99

Bouskill, N., Tang, J., Riley, W. J., and Brodie, E. L. (2012). Trait-based representation of biological nitrification: model development, testing, and predicted community composition. Front. Microbiol. 3:364. doi: 10.3389/fmicb.2012.00364

Brovkin, V., Van Bodegom, P. M., Kleinen, T., Wirth, C., Cornwell, W. K., Cornelissen, J. H. C., et al. (2012). Plant-driven variation in decomposition rates improves projections of global litter stock distribution. Biogeosciences 9, 565-576. doi: 10.5194/bg-9-565-2012

Bruno, J. F., Stachowicz, J. J., and Bertness, M. D. (2003). Inclusion of facilitation into ecological theory. Trends Ecol. Evol. 18, 119-125. doi: 10.1016/S01695347(02)00045-9

Cadotte, M. W., Cardinale, B. J., and Oakley, T. H. (2008). Evolutionary history and the effect of biodiversity on plant productivity. Proc. Natl. Acad. Sci. U.S.A. 105, 17012-17017. doi: 10.1073/pnas.0805962105

Caporaso, J. G., Lauber, C. L., Walters, W. A., Berg-Lyons, D., Lozupone, C. A., Turnbaugh, P. J., et al. (2011). Global patterns of $16 \mathrm{~S}$ rRNA diversity at a depth of millions of sequences per sample. Proc. Natl. Acad. Sci. 108, 4516-4522. doi: 10.1073/pnas.1000080107

Cardinale, B. J., Duffy, J. E., Gonzalez, A., Hooper, D. U., Perrings, C., Venail, P., et al. (2012). Biodiversity loss and its impact on humanity. Nature 486, 59-67. doi: 10.1038/Nature11148

Casey, J. R., Lomas, M. W., Mandecki, J., and Walker, D. E. (2007). Prochlorococcus contributes to new production in the Sargasso Sea deep chlorophyll maximum. Geophys. Res. Lett. 34:L10604. doi: 10.1029/2006GL028725

Chen, Y., Dumont, M. G., Neufeld, J. D., Bodrossy, L., Stralis-Pavese, N., McNamara, N. P., et al. (2008). Revealing the uncultivated majority: combining DNA stable-isotope probing, multiple displacement amplification and metagenomic analyses of uncultivated Methylocystis in acidic peatlands. Environ. Microbiol. 10, 2609-2622. doi: 10.1111/j.1462-2920.2008.01683.x

Cox, P., Wilkinson, S. P., and Anderson, J. M. (2001). Effects of fungal inocula on the decomposition of lignin and structural polysaccharides in Pinus sylvestris litter. Biol. Fert. Soils 33, 246-251. doi: 10.1007/s003740000315

Díaz, S., Lavorel, S., De Bello, F., Quétier, F., Grigulis, K., and Robson, T. M. (2007). Incorporating plant functional diversity effects in ecosystem service assessments. Proc. Natl. Acad. Sci. U.S.A. 104, 20684-20689. doi: 10.1073/pnas.0704716104

Edwards, K. F., Klausmeier, C. A., and Litchman, E. (2011). Evidence for a threeway trade-off between nitrogen and phosphorus competitive abilities and cell size in phytoplankton. Ecology 92, 2085-2095. doi: 10.1890/11-0395.1

Edwards, K. J., Becker, K., and Colwell, F. S. (2012). The deep, dark energy biosphere: intraterrestrial life on earth. Annu. Rev. Earth Planet. Sci. 40, 551-568. doi: 10.1146/annurev-earth-042711-105500

Fierer, N., Bradford, M. A., and Jackson, R. B. (2007). Toward an ecological classification of soil bacteria. Ecology 88, 1354-1364. doi: 10.1890/05-1839

Flynn, D. F. B., Mirotchnick, N., Jain, M., Palmer, M. I., and Naeem, S. (2011). Functional and phylogenetic diversity as predictors of biodiversity-ecosystemfunction relationships. Ecology 92, 1573-1581. doi: 10.1890/10-1245.1

Garcia, S. L., McMahon, K. D., Martinez-Garcia, M., Srivastava, A., Sczyrba, A., Stepanauskas, R., et al. (2013). Metabolic potential of a single cell belonging to one of the most abundant lineages in freshwater bacterioplankton. ISME J. 7, 137-147. doi: 10.1038/ismej.2012.86

Garland, J. L. (1996). Analytical approaches to the characterization of samples of microbial communities using patterns of potential C source utilization. Soil Biol. Biochem. 28, 213-221. doi: 10.1016/0038-0717(95)00112-3

Ghiglione, J. F., Galand, P. E., Pommier, T., Pedros-Alio, C., Maas, E. W., Bakker, K., et al. (2012). Pole-to-pole biogeography of surface and deep marine bacterial communities. Proc. Natl. Acad. Sci. U.S.A. 109, 17633-17638. doi: 10.1073/pnas.1208160109

Green, J. L., Bohannan, B. J. M., and Whitaker, R. J. (2008). Microbial biogeography: from taxonomy to traits. Science 320, 1039-1043. doi: 10.1126/science. 1153475

Griffiths, B. S., Kuan, H. L., Ritz, K., Glover, L. A., McCaig, A. E., and Fenwick, C. (2004). The relationship between microbial community structure and functional stability, tested experimentally in an upland pasture soil. Microb. Ecol. 47, 104-113. doi: 10.1007/s00248-002-2043-7

Griffiths, B. S., Ritz, K., Bardgett, R. D., Cook, R., Christensen, S., Ekelund, F., et al. (2000). Ecosystem response of pasture soil communities to fumigationinduced microbial diversity reductions: an examination of the biodiversityecosystem function relationship. Oikos 90, 279-294. doi: 10.1034/j.16000706.2000.900208.x

Grime, J. P. (1977). Evidence for the existence of three primary strategies in plants and its relevance to ecological and evolutionary theory. Am. Nat. 111, 1169-1194. doi: 10.2307/2460262

Haagensen, J. A., Regenberg, B., and Sternberg, C. (2011). Advanced microscopy of microbial cells. Adv. Biochem. Eng. Biotechnol. 124, 21-54. doi: 10.1007/10_2010_83

Hallin, S., Welsh, A., Stenstrom, J., Hallet, S., Enwall, K., Bru, D., et al., (2012). Soil functional operating range linked to microbial biodiversity and community composition using denitrifiers as model guild. PLoS ONE 7:e51962. doi: 10.1371/journal.pone.0051962

Hautier, Y., Niklaus, P. A., and Hector, A. (2009). Competition for light causes plant biodiversity loss after eutrophication. Science 324, 636-638. doi: 10.1126/science. 1169640

Hedberg, P., Saetre, P., Sundberg, S., Rydin, H., and Kotowski, W. (2013). A functional trait approach to fen restoration analysis. Appl. Veg. Sci. 16, 658-666. doi: 10.1111/Avsc. 12042

Ho, A., Kerckhof, F.-M., Luke, C., Reim, A., Krause, S., Boon, N., et al., (2013). Conceptualizing functional traits and ecological characteristics of methaneoxidizing bacteria as life strategies. Environ. Microbiol. Rep. 5, 335-345. doi: 10.1111/j.1758-2229.2012.00370.x

Hoehler, T. M., and Jorgensen, B. B. (2013). Microbial life under extreme energy limitation. Nat. Rev. Microbiol. 11, 83-94. doi: 10.1038/nrmicro2939

Hooper, D. U., Chapin, F. S., Ewel, J. J., Hector, A., Inchausti, P., Lavorel, S., et al. (2005). Effects of biodiversity on ecosystem functioning: a consensus of current knowledge. Ecol. Monogr. 75, 3-35. doi: 10.1890/04-0922

Huang, W. E., Stoecker, K., Griffiths, R., Newbold, L., Daims, H., Whiteley, A. S., et al. (2007). Raman-FISH: combining stable-isotope Raman spectroscopy and fluorescence in situ hybridization for the single cell analysis of identity and function. Environ. Microbiol. 9, 1878-1889. doi: 10.1111/j.1462-2920.2007. 01352.x

Hughes Martiny, J. B. H., Bohannan, B. J. M., Brown, J. H., Colwell, R. K., Fuhrman, J. A., Green, J. L., et al. (2006). Microbial biogeography: putting microorganisms on the map. Nat. Rev. Microbiol. 4, 102-112. doi: 10.1038/nrmicro1341 
Iverson, V., Morris, R. M., Frazar, C. D., Berthiaume, C. T., Morales, R. L., and Armbrust, E. V. (2012). Untangling genomes from metagenomes: revealing an uncultured class of marine euryarchaeota. Science 335, 587-590. doi: 10.1126/science. 1212665

Janzen, R. A., Dormaar, J. F., and McGill, W. B. (1995). A community-level concept of controls on decomposition processes: decomposition of barley straw by Phanerochaete chrysosporium or Phlebia radiata in pure or mixed culture. Soil Biol. Biochem. 27, 173-179. doi: 10.1016/0038-0717(94)00164-V

Jones, C. M., Welsh, A., Throbäck, I. N., Dörsch, P., Bakken, L. R., and Hallin, S. (2011). Phenotypic and genotypic heterogeneity among closely related soilborne $\mathrm{N}_{2}$ and $\mathrm{N}_{2} \mathrm{O}$-producing Bacillus isolates harboring the nos $\mathrm{Z}$ gene. FEMS Microbiol. Ecol. 76, 541-552. doi: 10.1111/j.1574-6941.2011.01071.x

Jones, S. E., and Lennon, J. T. (2010). Dormancy contributes to the maintenance of microbial diversity. Proc. Natl. Acad. Sci. U.S.A. 107, 5881-5886. doi: 10.1073/pnas.0912765107

Jonsson, L. M., Nilsson, M.-C., Wardle, D. A., and Zackrisson, O. (2001). Context dependent effects of ectomycorrhizal species richness on tree seedling productivity. Oikos 93, 353-364. doi: 10.1034/j.1600-0706.2001.930301.x

Jousset, A., Schmid, B., Scheu, S., and Eisenhauer, N. (2011). Genotypic richness and dissimilarity opposingly affect ecosystem functioning. Ecol. Lett. 14, 537-545. doi: 10.1111/j.1461-0248.2011.01613.x

Kattge, J., Díaz, S., Lavorel, S., Prentice, I. C., Leadley, P., Bönisch, G., et al. (2011). TRY - a global database of plant traits. Glob. Change Biol. 17, 2905-2935. doi: 10.1111/j.1365-2486.2011.02451.x

Koeppel, A., Perry, E. B., Sikorski, J., Krizanc, D., Warner, A., Ward, D. M., et al. (2008). Identifying the fundamental units of bacterial diversity: a paradigm shift to incorporate ecology into bacterial systematics. Proc. Natl. Acad. Sci. U.S.A. 105, 2504-2509. doi: 10.1073/pnas.0712205105

Lavorel, S., and Garnier, E. (2002). Predicting changes in community composition and ecosystem functioning from plant traits: revisiting the Holy Grail. Funct. Ecol. 16, 545-556. doi: 10.1046/j.1365-2435.2002.00664.x

Lavorel, S., Storkey, J., Bardgett, R. D., De Bello, F., Berg, M. P., Le Roux, X., et al. (2013). A novel framework for linking functional diversity of plants with other trophic levels for the quantification of ecosystem services. J. Veg. Sci. 24, 942-948. doi: 10.1111/Jvs.12083

Lennon, J. T., Aanderud, Z. T., Lehmkuhl, B. K., and Schoolmaster, D. R. Jr. (2012). Mapping the niche space of soil microorganisms using taxonomy and traits. Ecology 93, 1867-1879. doi: 10.1890/11-1745.1

Lennon, J. T., and Jones, S. E. (2011). Microbial seed banks: the ecological and evolutionary implications of dormancy. Nat. Rev. Microbiol. 119, 119-130. doi: 10.1038/nrmicro2504

Le Roux, X., Recous, S., and Attard, E. (2011). "Soil microbial diversity in grasslands and its importance for grassland functioning and services," in Grassland Productivity and Ecosystem Services, eds. G. Lemaire, J. Hodgson, and A. Chabbi (Wallingford: CAB International), 158-165.

Le Roux, X., Schmid, B., Poly, F., Barnard, R. L., Niklaus, P. A., Guillaumaud, N., et al. (2013). Soil environmental conditions and microbial build-up mediate the effect of plant diversity on soil nitrifying and denitrifying enzyme activities in temperate grasslands. PLoS ONE 8:e61069. doi: 10.1371/journal.pone.00 61069

Litchman, E., Klausmeier, C. A., Schofield, O. M., and Falkowski, P. G. (2007). The role of functional traits and trade-offs in structuring phytoplankton communities: scaling from cellular to ecosystem level. Ecol. Lett. 10, 1170-1181. doi: 10.1111/j.1461-0248.2007.01117.x

Loreau, M. (2000). Biodiversity and ecosystem functioning: recent theoretical advances. Oikos 91, 3-17. doi: 10.1034/j.1600-0706.2000.910101.x

Losos, J. B. (2008). Phylogenetic niche conservatism, phylogenetic signal and the relationship between phylogenetic relatedness and ecological similarity among species. Ecol. Lett. 11, 995-1003. doi: 10.1111/j.1461-0248.2008.01229.x

Mackelprang, R., Waldrop, M. P., Deangelis, K. M., David, M. M., Chavarria, K. L., Blazewicz, S. J., et al. (2011). Metagenomic analysis of a permafrost microbial community reveals a rapid response to thaw. Nature 480, 368-371. doi: 10.1038/Nature 10576

Martiny, A. C., Treseder, K., and Pusch, G. (2012). Phylogenetic conservatism of functional traits in microorganisms. ISME J. 7, 830-838. doi: 10.1038/ismej.2012.160

Mayali, X., Weber, P. K., Brodie, E. L., Mabery, S., Hoeprich, P. D., and Pett-Ridge, J. (2012). High-throughput isotopic analysis of RNA microarrays to quantify microbial resource use. ISME J. 6, 1210-1221. doi: 10.1038/ismej.2011.175
McGill, B. J., Enquist, B. J., Weiher, E., and Westoby, M. (2006). Rebuilding community ecology from functional traits. Trends Ecol. Evol. 21, 178-185. doi: 10.1016/j.tree.2006.02.002

Nemergut, D. R., Costello, E. K., Hamady, M., Lozupone, C., Jiang, L., Schmidt, S. K., et al. (2011). Global patterns in the biogeography of bacterial taxa. Environ. Microbiol. 13, 135-144. doi: 10.1111/j.1462-2920.2010.02315.x

Newton, R. J., Jones, S. E., Eiler, A., McMahon, K. D., and Bertilsson, S. (2011). A guide to the natural history of freshwater lake bacteria. Microbiol. Mol. Biol. Rev. 75, 14-49. doi: 10.1128/mmbr.00028-10

Nielsen, J. L., Christensen, D., Kloppenborg, M., and Nielsen, P. H. (2003). Quantification of cell-specific substrate uptake by probe-defined bacteria under in situ conditions by microautoradiography and fluorescence in situ hybridization. Environ. Microbiol. 5, 202-211. doi: 10.1046/j.1462-2920.2003.00402.x

Norberg, J., Swaney, D. P., Dushoff, J., Lin, J., Casagrandi, R., and Levin, S. A. (2001). Phenotypic diversity and ecosystem functioning in changing environments: a theoretical framework. Proc. Natl. Acad. Sci. U.S.A. 98, 11376-11381. doi: 10.1073/pnas.171315998

Patra, A. K., Abbadie, L., Clays-Josserand, A., Degrange, V., Grayston, S. J., Loiseau, P., et al. (2005). Effects of grazing on microbial functional groups involved in soil N dynamics. Ecol. Monogr. 75, 65-80. doi: 10.1890/03-0837

Peter, H., Beier, S., Bertilsson, S., Lindstrom, E. S., Langenheder, S., and Tranvik, L. J. (2011). Function-specific response to depletion of microbial diversity. ISME J. 5, 351-361. doi: 10.1038/ismej.2010.119

Philippot, L., Bru, D., Saby, N. P. A., Cuhel, J., Arrouays, D., Simek, M., et al. (2009). Spatial patterns of bacterial taxa in nature reflect ecological traits of deep branches of the 16S rRNA bacterial tree. Environ. Microbiol. 11, 3096-3104. doi: 10.1111/j.1462-2920.2009.02014.x

Philippot, L., Spor, A., Henault, C., Bru, D., Bizouard, F., Jones, C. M., et al. (2013) Loss in microbial diversity affects nitrogen cycling in soil. ISME J. 7, 1609-1619. doi: 10.1038/ismej.2013.34

Polz, M. F., Alm, E. J., and Hanage, W. P. (2013). Horizontal gene transfer and the evolution of bacterial and archaeal population structure. Trends Genet. 29, 170-175. doi: 10.1016/j.tig.2012.12.006

Portillo, M. C., Leff, J. W., Lauber, C. L., and Fierer, N. (2013). Cell size distributions of soil bacterial and archaeal taxa. Appl. Environ. Microbiol. 79, 7610-7617. doi: 10.1128/aem.02710-13

Prosser, J. I., Bohannan, B. J. M., Curtis, T. P., Ellis, R. J., Firestone, M. K., Freckleton, R. P., et al. (2007). The role of ecological theory in microbial ecology. Nat. Rev. Microbiol. 5, 384-392. doi: 10.1038/nrmicro1643

Raes, J., Letunic, I., Yamada, T., Jensen, L. J., and Bork, P. (2011). Toward molecular trait-based ecology through integration of biogeochemical, geographical and metagenomic data. Mol. Syst. Biol. 7:473. doi: 10.1038/msb.2011.6

Roscher, C., Schumacher, J., Gubsch, M., Lipowsky, A., Weigelt, A., Buchmann, N., et al. (2012). Using plant functional traits to explain diversity-productivity relationships. PLoS ONE 7:e36760. doi: 10.1371/journal.pone.0036760

Rusch, D. B., Martiny, A. C., Dupont, C. L., Halpern, A. L., and Venter, J. C. (2010). Characterization of Prochlorococcus clades from iron-depleted oceanic regions. Proc. Natl. Acad. Sci. U.S.A. 107, 16184-16189. doi: 10.1073/pnas.1009513107

Salles, J., Le Roux, X., and Poly, F. (2012). Relating phylogenetic and functional diversity among denitrifiers and quantifying their capacity to predict community functioning. Front. Microbiol. 3:209. doi: 10.3389/fmicb.2012. 00209

Salles, J. F., Poly, F., Schmid, B., and Roux, X. L. (2009). Community niche predicts the functioning of denitrifying bacterial assemblages. Ecology 90, 3324-3332. doi: 10.1890/09-0188.1

Schleifer, K. H. (2009). Classification of bacteria and archaea: past, present and future. Syst. Appl. Microbiol. 32, 533-542. doi: 10.1016/j.syapm.2009.09.002

Schmid, B. (2002). The species richness productivity controversy. Trends Ecol. Evol. 17, 113-114. doi: 10.1016/S0169-5347(01)02422-3

Spehn, E. M., Hector, A., Joshi, J., Scherer-Lorenzen, M., Schmid, B., BazeleyWhite, E., et al. (2005). Ecosystem effects of biodiversity manipulations in European grasslands. Ecol. Monogr. 75, 37-63. doi: 10.1890/03-4101

Staley, J. T. (2006). The bacterial species dilemma and the genomic-phylogenetic species concept. Philos. Trans. R. Soc. Lond. B. Biol. Sci. 361, 1899-1909. doi: $10.1098 /$ rstb.2006.1914

Stepanauskas, R. (2012). Single cell genomics: an individual look at microbes. Curr.Opin. Microbiol. 15, 613-620. doi: 10.1016/j.mib.2012.09.001

Stiehl-Braun, P. A., Hartmann, A. A., Kandeler, E., Buchmann, N., and Niklaus, P. A. (2011). Interactive effects of drought and $\mathrm{N}$ fertilization on the spatial 
distribution of methane assimilation in grassland soils. Glob. Change Biol. 17, 2629-2639. doi: 10.1111/j.1365-2486.2011.02410.x

Tilman, D. (1997). The influence of functional diversity and composition on ecosystem processes. Science 277, 1300-1302. doi: 10.1126/science. 277.5330 .1300

Torsvik, V., Ovreas, L., and Thingstad, T. F. (2002). Prokaryotic diversityMagnitude, dynamics, and controlling factors. Science 296, 1064-1066. doi: 10.1126/science. 1071698

Treseder, K. K., Kivlin, S. N., and Hawkes, C. V. (2011). Evolutionary trade-offs among decomposers determine responses to nitrogen enrichment. Ecol. Lett. 14, 933-938. doi: 10.1111/j.1461-0248.2011.01650.x

Van Der Gucht, K., Cottenie, K., Muylaert, K., Vloemans, N., Cousin, S., Declerck, S., et al. (2007). The power of species sorting: local factors drive bacterial community composition over a wide range of spatial scales. Proc. Natl. Acad. Sci. U.S.A. 104, 20404-20409. doi: 10.1073/pnas.0707200104

Van Der Heijden, M. G. A., Klironomos, J. N., Ursic, M., Moutoglis, P., StreitwolfEngel, R., Boller, T., et al. (1998). Mycorrhizal fungal diversity determines plant biodiversity, ecosystem variability and productivity. Nature 396, 69-72. doi: $10.1038 / 23932$

Violle, C., Navas, M. L., Vile, D., Kazakou, E., Fortunel, C., Hummel, I., et al. (2007). Let the concept of trait be functional! Oikos 116, 882-892. doi: 10.1111/j.2007.0030-1299.15559.x

Von Mering, C., Hugenholtz, P., Raes, J., Tringe, S. G., Doerks, T., Jensen, L. J., et al. (2007). Quantitative phylogenetic assessment of microbial communities in diverse environments. Science 315, 1126-1130. doi: 10.1126/science. 1133420

Wallenstein, M. D., and Hall, E. K. (2012). A trait-based framework for predicting when and where microbial adaptation to climate change will affect ecosystem functioning. Biogeochemistry 109, 35-47. doi: 10.1007/s10533-011-9641-8

Watrous, J. D., Phelan, V. V., Hsu, C.-C., Moree, W. J., Duggan, B. M., Alexandrov, T., et al. (2013). Microbial metabolic exchange in 3D. ISME J. 7, 770-780. doi: 10.1038/ismej.2012.155

Webster, G., Embley, T. M., Freitag, T. E., Smith, Z., and Prosser, J. I. (2005). Links between ammonia oxidizer species composition, functional diversity and nitrification kinetics in grassland soils. Environ. Microbiol. 7, 676-684. doi: 10.1111/j.1462-2920.2005.00740.x
Wertz, S., Degrange, V., Prosser, J. I., Poly, F., Commeaux, C., Guillaumaud, N., et al. (2007). Decline of soil microbial diversity does not influence the resistance and resilience of key soil microbial functional groups following a model disturbance. Environ. Microbiol. 9, 2211-2219. doi: 10.1111/j.1462-2920.2007.01335.x

Wittebolle, L., Marzorati, M., Clement, L., Balloi, A., Daffonchio, D., Heylen, K., et al. (2009). Initial community evenness favours functionality under selective stress. Nature 458, 623-626. doi: 10.1038/nature07840

Wohl, D. L., Arora, S., and Gladstone, J. R. (2004). Functional redundancy supports biodiversity and ecosystem function in a closed and constant environment. Ecology 85, 1534-1540. doi: 10.1890/03-3050

Wrighton, K. C., Thomas, B. C., Sharon, I., Miller, C. S., Castelle, C. J., Verberkmoes, N. C., et al. (2012). Fermentation, hydrogen, and sulfur metabolism in multiple uncultivated bacterial phyla. Science 337, 1661-1665. doi: 10.1126/science.1224041

Zhu, Y., Chen, H., Fan, J., Wang, Y., Li, Y., Chen, J., et al. (2000). Genetic diversity and disease control in rice. Nature 406, 718-722. doi: 10.1038/35021046

Conflict of Interest Statement: The authors declare that the research was conducted in the absence of any commercial or financial relationships that could be construed as a potential conflict of interest.

Received: 31 March 2014; paper pending published: 25 April 2014; accepted: 07 May 2014; published online: 27 May 2014.

Citation: Krause S, Le Roux X, Niklaus PA, Van Bodegom PM, Lennon JT, Bertilsson S, Grossart H-P, Philippot L and Bodelier PLE (2014) Trait-based approaches for understanding microbial biodiversity and ecosystem functioning. Front. Microbiol. 5:251. doi: $10.3389 /$ fmicb.2014.00251

This article was submitted to Aquatic Microbiology, a section of the journal Frontiers in Microbiology.

Copyright (c) 2014 Krause, Le Roux, Niklaus, Van Bodegom, Lennon, Bertilsson, Grossart, Philippot and Bodelier. This is an open-access article distributed under the terms of the Creative Commons Attribution License (CC BY). The use, distribution or reproduction in other forums is permitted, provided the original author(s) or licensor are credited and that the original publication in this journal is cited, in accordance with accepted academic practice. No use, distribution or reproduction is permitted which does not comply with these terms. 